\title{
Long-chain haloalkanes are incorporated into fatty acids by Rhodococcus rhodochrous NCIMB 13064
}

\author{
John T. G. Hamilton, ${ }^{1}$ W. Colin McRoberts, ${ }^{1}$ Michael J. Larkin ${ }^{2,3}$ and \\ David B. Harper ${ }^{1,4}$
}

Author for correspondence: David B. Harper. Tel: +44 1232250666 ext. 55343. Fax: +44 1232669551.

\footnotetext{
1 Food Science Division, Department of Agriculture for Northern Ireland, Newforge Lane, Belfast BT9 5PX, UK

2 The QUESTOR Centre, David Keir Building, The Queen's University of Belfast, Belfast BT9 5AG, UK

3 School of Biology and Biochemistry, David Keir Building, The Queen's University of Belfast, Belfast BT9 5AG, UK

4 Microbial Biochemistry Section, Department of Food Science, The Queen's University of Belfast, Newforge Lane, Belfast BT9 5PX, UK
}

\begin{abstract}
The fatty acid composition of the cellular lipids of Rhodococcus rhodochrous NCIMB 13064 grown on various long-chain haloalkanes has been investigated and the influence of halogen substituents, carbon chain length and the position of halogen substitution in the growth substrate explored. Of the total fatty acids present in cells grown on 1-chloro-, 1-bromo- and 1iodohexadecane, 75, 90 and $81 \%$, respectively, were substituted in the $\omega$ position by the corresponding halogen but only $1 \%$ of the fatty acids present after growth on 1-fluorotetradecane were fluorinated in this position. The extent of the halofatty acid incorporation with different halogen substituents in the growth substrate appears to reflect the degree to which oxygenase attack is restricted to the non-halogenated end of the haloalkane. Studies of the fatty acid composition of cells after growth on a series of 1-chloroalkanes containing an even number of carbon atoms between $C_{10}$ and $C_{18}$ indicated chlorofatty acid incorporation from $C_{12}$ to $C_{18}$ substrates at levels ranging from $21 \%$ with $C_{12}$ to $75 \%$ with $C_{16}$. The chlorofatty acids formed by initial oxidation of the chloroalkane were chain-lengthened or chain-shortened by from two to eight carbon atoms, with accompanying desaturation in some instances. Substantial quantities of a methyl-branched $C_{19: 0}$ chlorofatty acid were also present with several chloroalkane substrates. When the fatty acid composition of cells after growth on 1-bromoalkanes containing an odd number of carbon atoms between $C_{11}$ and $C_{17}$ was examined, the incorporation of bromofatty acids was observed with $C_{13}, C_{15}$ and $C_{17}$ substrates; a maximum of $76 \%$ was recorded for the $C_{15}$ bromoalkane. As with even chain-length chloroalkanes, both chain-lengthening and -shortening occurred predominantly via twocarbon units so that most bromoacids present possessed an odd number of carbon atoms. When 1-bromododecane or 2-bromododecane were substrates, overall incorporations of bromofatty acids into the lipid fraction were very similar, demonstrating that the position of halogen substitution in the haloalkane was not critical in determining the extent of incorporation of the haloacids into cellular lipids. The results of the study indicate a mechanism by which degradation products of chlorinated paraffins could enter the biological food chain.
\end{abstract}

Keywords: Rbodococcus rbodocbrous, long-chain haloalkanes, $\omega$-halofatty acids, cellular lipids

\section{INTRODUCTION}

Mycobacterium spp. grown on long-chain chloroalkanes, such as 1-chlorohexadecane, as sole carbon source directly incorporate the compounds as the corresponding $\omega$ chlorofatty acids into the cellular lipid fraction of the organism. Transformation into chlorinated fatty acids of both longer and shorter chain length, and desaturation occur such that $\omega$-chlorofatty acids comprise as much as $85 \%$ of the total fatty acid content of the organism (Murphy \& Perry, 1983). Similarly, 1-chloroalkanes are incorporated in substantial quantities into the cellular 
fatty acid fraction of the filamentous fungi Cunninghamella elegans and Penicillium ronatum, and the yeast Candida lipolytica (Murphy \& Perry, 1984). The fate of organic chlorine in the growth substrate not incorporated into the lipid fraction was not investigated in these studies but clearly, for the chloroalkane to act as a carbon source, such organisms must be capable of at least partial catabolism of the carbon chain of the chloroalkane.

A new insight into this area arose from recent work on Rhodococcus rbodocbrous NCIMB 13064, an organism capable of utilizing a wide range of haloalkanes as sole carbon source (Curragh et al., 1994). Whilst catabolism of short chain chloroalkanes by this organism is initiated by a hydrolytic dehalogenase, it appears that attack on chloroalkanes with a chain length above $\mathrm{C}_{10}$ is initiated by an oxygenase at the non-dehalogenated end of the molecule, leading to the formation of $\omega$-chlorofatty acids. These compounds are degraded by subsequent $\beta$-oxidation to 4-chlorobutyric acid which is chemically lactonized with the elimination of chloride to form $\gamma$ butyrolactone. Notwithstanding the ability of the bacterium to dehalogenate the substrate completely, analysis of the cellular fatty acid composition after growth on 1chlorohexadecane indicated that $\omega$-chlorofatty acids constituted approximately $75 \%$ of the total fatty acid content with $C_{14: 0}, C_{16: 0}, C_{16: 1}$ and $C_{18: 1}$ acids predominating. This surprising accumulation of halolipids in an organism potentially capable of total mineralization of the haloalkane is not only of considerable significance in the biological treatment of industrial effluents, but has more general environmental implications.

In this paper we explore the influence of carbon chain length, the nature of the halogen substituent and the position of halogen substitution in the haloalkane growth substrate on the fatty acid composition of the cellular lipids of R. rbodochrous NCIMB 13064.

\section{METHODS}

Organism and culture. Rbodococcus rbodocbrous NCIMB 13064 was grown routinely in $500 \mathrm{ml}$ conical flasks containing $200 \mathrm{ml}$ medium of the following composition $\left(\mathrm{g} \mathrm{l}^{-1}\right): \mathrm{NaH}_{2} \mathrm{PO}_{4} \cdot 2 \mathrm{H}_{2} \mathrm{O}$, $1 \cdot 6 ; \mathrm{Na}_{2} \mathrm{HPO}_{4}, 1 \cdot 4 ;\left(\mathrm{NH}_{4}\right)_{2} \mathrm{SO}_{4}, 0 \cdot 5 ; \mathrm{MgSO}_{4} .7 \mathrm{H}_{2} \mathrm{O}, 0 \cdot 2 ; \mathrm{K}_{2} \mathrm{SO}_{4}$ $0 \cdot 5$. The $\mathrm{pH}$ of the solution was adjusted to $7 \cdot 0$ and the medium supplemented with a trace element solution $\left(10 \mathrm{ml} \mathrm{l}^{-1}\right)$ containing $\left(\mathrm{g} \mathrm{l}^{-1}\right): \mathrm{Na}_{2}$ EDTA. $2 \mathrm{H}_{2} \mathrm{O}, 12 \cdot 0 ; \mathrm{FeSO}_{4} \cdot 7 \mathrm{H}_{2} \mathrm{O}, 2 \cdot 0$; $\mathrm{CaCl}_{2}, 1.0 ; \mathrm{ZnSO}_{4} .7 \mathrm{H}_{2} \mathrm{O}, 0.4 ; \mathrm{MnSO}_{4} .4 \mathrm{H}_{2} \mathrm{O}, 0.4$; $\mathrm{CuSO}_{4} \cdot 5 \mathrm{H}_{2} \mathrm{O}, 0 \cdot 1$. Haloalkane $(1 \mathrm{mmol})$ was added and the flasks, stoppered with cotton wool, were incubated on an orbital shaker (200 r.p.m.) at $25^{\circ} \mathrm{C}$ except when certain $\omega$-bromoalkanes were employed as substrates when an incubation temperature of $30^{\circ} \mathrm{C}$ was used to ensure that the compounds remained in the liquid phase and were adequately dispersed in the culture medium.

Chemicals. All alkanes, chloroalkanes, iodoalkanes and most bromoalkanes were obtained from Aldrich. Purity was in all cases $>95 \%$ and in many instances $>98 \%$. 1Bromopentadecane (purity $>98 \%$ ) and 1-bromoheptadecane (purity $>97 \%$ ) were acquired from Fluka. 1-Fluorotetradecane (purity $>96 \%$ ) was obtained from Fluorochem. None of the halogenated alkanes employed as substrates contained halo- genated impurities at levels above the limit of detection using gas chromatography/mass spectrometry, i.e. $0 \cdot 5 \%$.

Determination of fatty acid composition of cellular lipids. When growth on the haloalkane substrate was complete in the early stationary phase, cells $(5 \mathrm{~g}$ wet $\mathrm{wt}$ ) were harvested by centrifugation, washed with petroleum ether (b.p. $40-60^{\circ} \mathrm{C}$, $3 \times 20 \mathrm{ml}$ ) to remove residual substrate and cellular fatty acids were converted directly to the corresponding methyl esters by the transesterification technique of Dunlap \& Perry (1967). Wet cells $\left(1 \mathrm{~g}\right.$ wet wt) were suspended in $14 \% \mathrm{BF}_{3}$ in methanol/ benzene $(9: 1, \mathrm{v} / \mathrm{v}, 4 \mathrm{ml})$ and heated for $12 \mathrm{~h}$ at $60^{\circ} \mathrm{C}$ in a water bath in a glass-stoppered tube. After cooling, water $(8 \mathrm{ml})$ was added and the mixture extracted with petroleum ether (b.p. $\left.40-60^{\circ} \mathrm{C}, 2 \times 10 \mathrm{ml}\right)$. The extracts were combined, washed with water $(10 \mathrm{ml})$ and concentrated to $1 \mathrm{ml}$.

Fatty acid methyl esters (FAME) were identified and quantified by gas chromatography/mass spectrometry on a Hewlett Packard 5890 gas chromatograph linked to a HP 5970 mass selective detector controlled by an HP 300 series computer. The gas chromatograph was fitted with a CP-SIL-19 fused silica WCOT column ( $25 \mathrm{~m} \times 0.25 \mathrm{~mm}$ ) with $7 \%$ cyanopropyl, $7 \%$ phenyl, $85 \%$ methyl, $1 \%$ vinyl-polysiloxane as bonded phase. Helium was used as the carrier gas at a flow rate of $0.75 \mathrm{ml}$ $\mathrm{min}^{-1}$. In the acquisition of chemical ionization spectra, methane was bled into the source at a flow rate of $0.25 \mathrm{ml} \mathrm{min}^{-1}$. After a splitless injection of the sample, the oven temperature was held at $40^{\circ} \mathrm{C}$ for $1 \mathrm{~min}$, then programmed at $10^{\circ} \mathrm{C} \mathrm{min}{ }^{-1}$ up to $300^{\circ} \mathrm{C}$ and held at this temperature for $10 \mathrm{~min}$. Ion currents between $\mathrm{m} / \mathrm{e} 30$ and 500 were monitored. Individual FAME were identified from their electron impact (EI) and chemical ionization (CI) mass spectra and retention times (Murphy \& Perry, 1983). To quantify each FAME, the total ion current in the electron impact mode was expressed as a percentage of the sum of the ion currents associated with all the FAME in the extract with an abundance greater than $1 \%$ of the total. In Tables of fatty acid composition in Results and Discussion, only fatty acids present at concentrations $>1 \%$ are listed.

\section{RESULTS AND DISCUSSION}

\section{Effect of halogen substituent}

The fatty acid composition of $R$. rhodochrous cells harvested after growth on $\omega$-haloalkanes containing different halogen substituents is shown in Table 1. As previously reported (Curragh et al., 1994), extensive incorporation of chlorofatty acids into the lipid fraction was observed after growth on 1-chlorohexadecane. Surprisingly, the proportion of halofatty acids present was even greater after growth on hexadecanes with the sterically bulkier bromoand iodo-substituents. Substantial incorporation was observed in each case into the $C_{14: 0}, C_{16: 0}, C_{16: 1}$ and $C_{18: 1}$ fractions with the overall proportion of halofatty acids exceeding $90 \%$ when 1 -bromohexadecane was substrate. With increased size of the halogen substituent there was evidence of a trend toward greater accumulation of halofatty acids of shorter chain length. Thus, whilst the lipid fraction of 1-chlorohexadecane grown cells contained approximately $17 \%$ of the $\mathrm{C}_{14: 0}$ chloroacid, the corresponding iodoacid comprised $54 \%$ of the fraction in 1-iodohexadecane-grown cells.

Because neither 1-fluorohexadecane nor 1-bromo and 1iodo-tetradecanes were commercially available, the effect 
Table 1. Fatty acid composition of $R$. rhodochrous after growth at $25^{\circ} \mathrm{C}$ on different $\omega$-haloalkanes

Values are expressed as the percentage of total fatty acid content. Abbreviations: Non Hal, non-halogenated fatty acid; F, $\omega$-fluorofatty acid; $\mathrm{Cl}, \omega$-chlorofatty acid; $\mathrm{Br}, \omega$-bromofatty acid; $\mathrm{I}, \omega$-iodofatty acid; $\mathrm{Me}$, methyl-branched fatty acid.

\begin{tabular}{|c|c|c|c|c|c|c|c|c|}
\hline \multirow[t]{3}{*}{ Fatty acid } & \multicolumn{8}{|c|}{ Growth substrate } \\
\hline & \multicolumn{2}{|c|}{ 1-Fluorotetradecane } & \multicolumn{2}{|c|}{ 1-Chlorohexadecane } & \multicolumn{2}{|c|}{ 1-Bromohexadecane } & \multicolumn{2}{|c|}{ 1-Iodohexadecane } \\
\hline & Non Hal & $\mathbf{F}$ & Non Hal & $\mathrm{Cl}$ & Non Hal & $\mathbf{B r}$ & Non Hal & $\mathbf{I}$ \\
\hline$C_{8: 0}$ & $2 \cdot 5$ & - & - & $4 \cdot 7$ & - & - & - & - \\
\hline $\mathrm{C}_{10: 0}$ & $5 \cdot 3$ & - & - & $3 \cdot 8$ & - & - & - & - \\
\hline $\mathrm{C}_{12: 0}$ & - & - & - & - & - & - & - & - \\
\hline$C_{14: 0}$ & $39 \cdot 4$ & $1 \cdot 0$ & $1 \cdot 2$ & $16 \cdot 6$ & - & $27 \cdot 7$ & - & $53 \cdot 8$ \\
\hline $\mathrm{C}_{14: 1}$ & $2 \cdot 9$ & - & - & - & - & - & - & - \\
\hline$C_{15: 0}$ & - & - & $2 \cdot 1$ & $1 \cdot 6$ & $1 \cdot 1$ & $4 \cdot 1$ & $1 \cdot 3$ & - \\
\hline$C_{16: 0}$ & $7 \cdot 5$ & - & $15 \cdot 3$ & $27 \cdot 7$ & $4 \cdot 6$ & $22 \cdot 3$ & $12 \cdot 6$ & $9 \cdot 7$ \\
\hline$C_{16: 1}$ & $1 \cdot 0$ & - & $3 \cdot 0$ & $10 \cdot 3$ & - & $16 \cdot 0$ & - & $12 \cdot 7$ \\
\hline$C_{17: 0}$ & - & - & - & - & - & $7 \cdot 3$ & - & $1 \cdot 1$ \\
\hline$C_{18: 1}$ & $25 \cdot 7$ & - & $3 \cdot 7$ & $10 \cdot 0$ & $1 \cdot 4$ & $9 \cdot 8$ & $2 \cdot 4$ & $3 \cdot 6$ \\
\hline $\mathrm{C}_{19: 0} \mathrm{Me}$ & $12 \cdot 6$ & - & - & - & $2 \cdot 7$ & $1 \cdot 9$ & $2 \cdot 8$ & - \\
\hline$C_{20: 0}$ & - & - & - & - & - & $1 \cdot 1$ & - & - \\
\hline$C_{20: 1}$ & $2 \cdot 1$ & - & - & - & - & - & - & - \\
\hline Total & $99 \cdot 0$ & 1.0 & $25 \cdot 3$ & $74 \cdot 7$ & $9 \cdot 8$ & $90 \cdot 2$ & $19 \cdot 1$ & $80 \cdot 9$ \\
\hline
\end{tabular}

of fluorine substitution could not be compared directly with that of other halogens in alkanes of the same carbon chain lengths. Nevertheless, since only a relatively small difference between the overall levels of halofatty acid incorporation was observed with 1-halohexadecane and 1-halotetradecane as growth substrates (Table 2), 1-fluorotetradecane was employed as a substitute for 1fluorohexadecane as growth substrate in the comparison in Table 1. The sole fluorofatty acid detected in 1fluorotetradecane-grown cells was the $\mathrm{C}_{14: 0}$ compound and represented only $1 \%$ of the total fatty acids. When considered in the light of the results with other haloalkanes, this suggests that the size of the halogen substituent in the growth substrate may be one of the most important factors in determining the extent of halofatty acid incorporation. Paradoxically, the presence of a large halogen substituent actually appears to increase the likelihood that a fatty acid will be incorporated into the cellular lipid fraction, a finding which could be construed as implying a highly unusual substrate specificity for the process. However, factors influencing the initial formation of halofatty acids from the haloalkane must also be considered in interpreting this finding. Curragh et al. (1994) concluded that the degradation of $\omega$ chloroalkanes with chain lengths of $\mathrm{C}_{12}$ and above by $R$. rbodocbrous was initiated mainly by oxygenase attack at the non-halogenated end of the alkane molecule. This conclusion does not rule out the possibility that the specificity of the oxygenase may be sufficiently relaxed for it to be capable of attacking the halogenated end of the molecule as well. Other investigators (Omori \& Alexander, 1978; Yokota et al., 1986) have attributed release of chloride from 1,9-dichlorononane by resting cells of several $n$ - alkane-utilizing bacteria to this type of enzyme action. Such attack would be particularly favoured if the halogen substituent has relatively minor steric effects as in the case of fluorine. Indeed, it is quite conceivable that in $R$. rhodocbrous the strong polarization of the $\mathrm{C}-\mathrm{F}$ bond associated with electron withdrawal by the fluorine substituent can result in attack predominantly focused on the fluorinated end of the fluorotetradecane molecule with consequent defluorination and the formation of a nonsubstituted fatty acid. Thus, the failure to observe appreciable incorporation of fluorine into the lipid fraction during growth of $R$. rhodocbrous on 1fluorotetradecane may be attributable to the absence of significant fluorofatty acid formation during growth on this substrate. Similarly, the differing incorporation of $\omega$ chloro, -bromo and iodofatty acids into cellular lipids may merely reflect the degree to which oxygenase attack is restricted to the non-halogenated end of the haloalkane rather than any intrinsic selectivity in utilization of the acids in lipid synthesis.

\section{Effect of chain length}

Table 2 shows the fatty acid composition of $R$. rbodocbrous cells harvested after growth on a series of $\omega$-chloroalkanes with even numbers of carbon atoms. Chlorofatty acids were incorporated into the lipid fraction during growth on haloalkanes between $\mathrm{C}_{12}$ and $\mathrm{C}_{18}$ at levels ranging from $21 \%$ with $\mathrm{C}_{12}$ to $75 \%$ at $\mathrm{C}_{16}$. No chlorofatty acids were detected after growth on $\mathrm{C}_{10}$ or lower alkanes. As previously reported by Curragh et al. (1994) using 1chlorohexadecane as substrate, the chlorofatty acid formed by initial oxidation of the alkane appears, in each 
Table 2. Fatty acid composition of $R$. rhodochrous after growth at $25^{\circ} \mathrm{C}$ on $\omega$-chloroalkanes with even number carbon chains between $C_{10}$ and $C_{18}$

Values are expressed as the percentage of total fatty acid content. Abbreviations: Non $\mathrm{Cl}$, non-chlorinated fatty acid; $\mathrm{Cl}, \omega$-chlorofatty acid; Me, methyl-branched fatty acid.

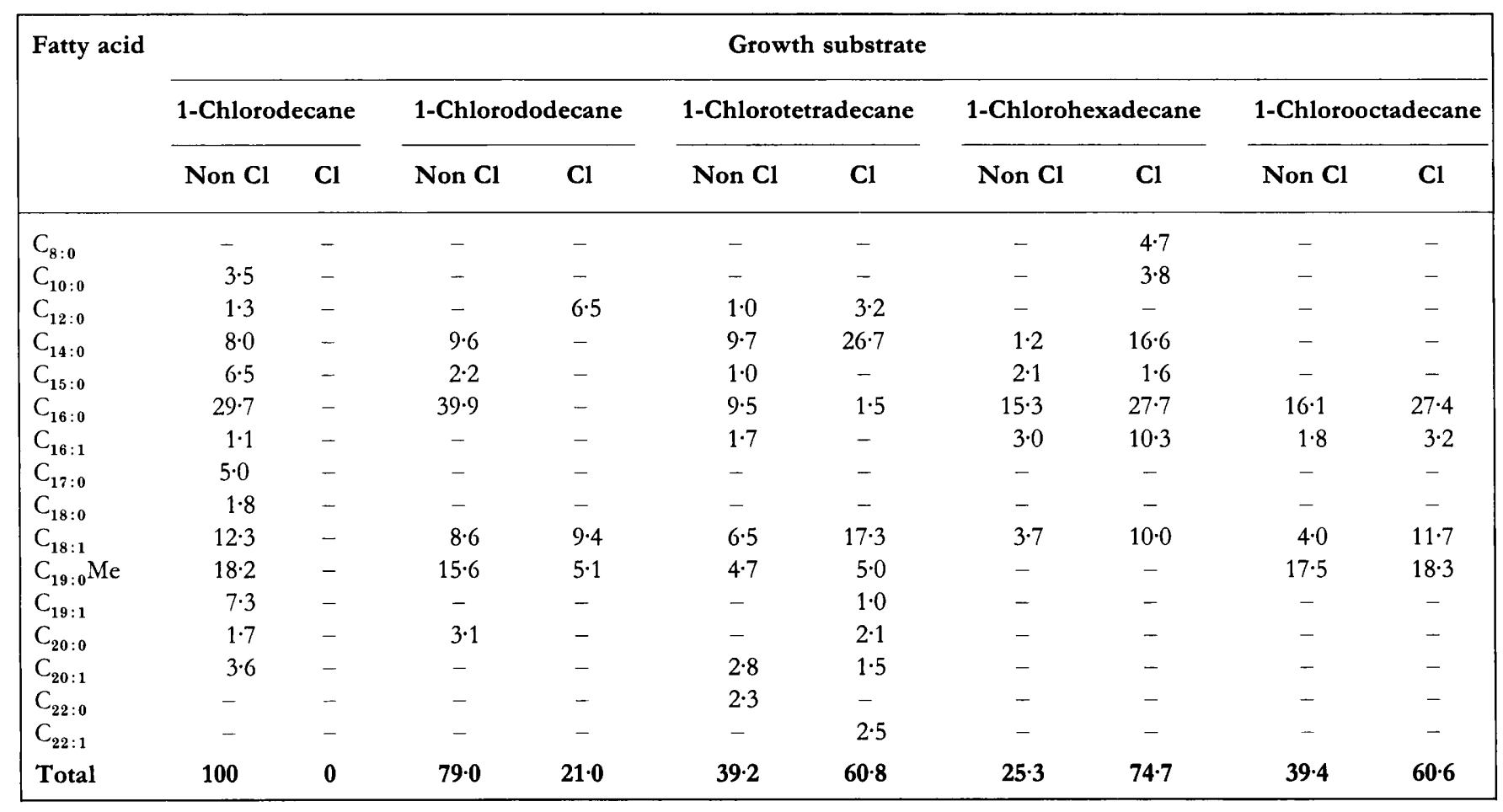

case, to be converted to chlorofatty acids of both longer and shorter chain length. With $\mathrm{C}_{12}$ and $\mathrm{C}_{14}$ chloroalkanes, chain lengthening predominated, whilst with the $\mathrm{C}_{18}$ chloroalkane, chain shortening prevailed. The $\mathrm{C}_{16}$ chloroalkane was subject to both processes in approximately equal measure. Desaturation also occurred readily, leading to the formation of the $\mathrm{C}_{18: 1}$ chlorofatty acid with $\mathrm{C}_{12}$ and $\mathrm{C}_{14}$ chloroalkanes and both $\mathrm{C}_{16: 1}$ and $\mathrm{C}_{18: 1}$ chlorofatty acids with $\mathrm{C}_{16}$ and $\mathrm{C}_{18}$ chloroalkanes.

A methyl-branched $\mathrm{C}_{19: 0}$ chlorofatty acid was present when $\mathrm{C}_{12}, \mathrm{C}_{14}$ and $\mathrm{C}_{18}$ chloroalkanes were substrates; it was particularly abundant in 1-chlorooctadecane-grown cells where, together with its non-halogenated analogue, it constituted $36 \%$ of the total fatty acids. It is interesting to note that where such methyl-branched chloroacids were found, substantial quantities of the unsaturated chlorofatty acids with a carbon chain one carbon shorter were present. This is consistent with the results of King \& Perry (1975) which indicated that the $\mathrm{C}_{\mathbf{1 0}}$ methyl group in branched $\mathrm{C}_{17}, \mathrm{C}_{18}$ and $\mathrm{C}_{19}$ fatty acids was derived by addition of the methyl group from $S$-adenosylmethionine across the double bond of the $\Delta 9$ unsaturated homologue.

Although longer chain $\omega$-chloroalkanes with an odd carbon chain length were not available commercially, the corresponding bromo-compounds with chain length between $\mathrm{C}_{11}$ and $\mathrm{C}_{17}$ were employed as growth substrates for R. rbodocbrous. However, the higher melting points of the longer chain bromoalkanes necessitated growth at $30^{\circ} \mathrm{C}$ rather than the temperature of $25^{\circ} \mathrm{C}$ utilized for growth on chloroalkanes. Bromofatty acids were incorporated into the lipid fraction during growth on 1-bromoalkanes between $\mathrm{C}_{13}$ and $\mathrm{C}_{17}$ (Table 3). Maximum incorporation of $76 \%$ was observed at $C_{15}$, a finding consistent with the $\mathrm{C}_{16}$ maximum recorded for even carbon chain length 1 chloroalkanes (Table 2). As with the latter series, chain lengthening and chain shortening occurred in two-carbon units so that most bromoacids present possessed an odd number of carbon atoms. Desaturation resulted in the accumulation of substantial quantities of the $\mathrm{C}_{17: 1}$ and $\mathrm{C}_{19: 1}$ bromoacids after growth on several of the bromoalkanes. The formation of a methyl-branched $\mathrm{C}_{18: 0}$ bromoacid in large quantities in cells grown on $\mathrm{C}_{13}, \mathrm{C}_{15}$ and $\mathrm{C}_{17}$ bromoalkanes mirrored the biosynthesis of methyl-branched $\mathrm{C}_{\mathbf{1 9 : 0}}$ chloroacid from the even carbon chain length chloroalkane-grown cells.

Although, for the reason outlined above, it was not practical to conduct growth experiments at temperatures less than $30^{\circ} \mathrm{C}$ with all the bromoalkanes, it was possible to employ both $\mathrm{C}_{11}$ and $\mathrm{C}_{15}$ 1-bromoalkanes as growth substrates at $25^{\circ} \mathrm{C}$. Significantly increased bromoacid incorporation was apparent with both substrates at the lower temperature with total bromoacid content for $\mathrm{C}_{11} 1$ bromoalkane-grown cells rising from $0 \%$ at $30{ }^{\circ} \mathrm{C}$ to $12.7 \%$ at $25^{\circ} \mathrm{C}$, and for $\mathrm{C}_{15} 1$-bromoalkane-grown cells from $76.1 \%$ at $30{ }^{\circ} \mathrm{C}$ to $83.9 \%$ at $25^{\circ} \mathrm{C}$. In view of the 
Table 3. Fatty acid composition of $R$. rhodochrous after growth at $30^{\circ} \mathrm{C}$ on $\omega$-bromoalkanes with odd number carbon chains between $\mathrm{C}_{11}$ and $\mathrm{C}_{17}$

Values are expressed as the percentage of total fatty acid content. Abbreviations: Non Br, non-brominated fatty acid; $\omega$ Br, $\omega$-bromofatty acid; Me, methyl-branched fatty acid.

\begin{tabular}{|c|c|c|c|c|c|c|c|c|}
\hline \multirow[t]{3}{*}{ Fatty acid } & \multicolumn{8}{|c|}{ Growth substrate } \\
\hline & \multicolumn{2}{|c|}{ 1-Bromoundecane } & \multicolumn{2}{|c|}{ 1-Bromotridecane } & \multicolumn{2}{|c|}{ 1-Bromopentadecane } & \multicolumn{2}{|c|}{ 1-Bromoheptadecane } \\
\hline & Non $\mathrm{Br}$ & $\mathrm{Br}$ & Non $\mathrm{Br}$ & $\mathbf{B r}$ & Non Br & $\mathrm{Br}$ & Non $\mathrm{Br}$ & $\mathbf{B r}$ \\
\hline$C_{7: 0}$ & - & - & - & $1 \cdot 6$ & - & - & - & - \\
\hline$C_{9: 0}$ & $3 \cdot 9$ & - & 8.5 & $5 \cdot 9$ & - & - & - & - \\
\hline$C_{11: 0}$ & $5 \cdot 8$ & - & $4 \cdot 1$ & - & - & - & - & - \\
\hline$C_{13: 0}$ & - & - & $9 \cdot 3$ & $10 \cdot 7$ & - & $1 \cdot 1$ & - & - \\
\hline$C_{14: 0}$ & $6 \cdot 2$ & - & $1 \cdot 7$ & -- & - & $1 \cdot 3$ & $1 \cdot 6$ & - \\
\hline$C_{15: 0}$ & $9 \cdot 7$ & - & $10 \cdot 0$ & $3 \cdot 3$ & $21 \cdot 9$ & $34 \cdot 3$ & $10 \cdot 3$ & $37 \cdot 0$ \\
\hline$C_{15: 1}$ & - & - & - & - & $1 \cdot 0$ & $4 \cdot 3$ & - & $2 \cdot 3$ \\
\hline$C_{16: 0}$ & $31 \cdot 5$ & - & $11 \cdot 5$ & - & - & - & 8.8 & - \\
\hline$C_{16: 1}$ & $2 \cdot 6$ & - & - & - & - & - & - & - \\
\hline$C_{17: 0}$ & $5 \cdot 0$ & - & $3 \cdot 3$ & - & - & - & $5 \cdot 8$ & $1 \cdot 2$ \\
\hline$C_{17: 1}$ & $2 \cdot 0$ & - & $1 \cdot 8$ & 6.0 & - & $11 \cdot 4$ & - & $14 \cdot 2$ \\
\hline$C_{18: 0}$ & $1 \cdot 0$ & - & - & -- & - & - & - & - \\
\hline $\mathrm{C}_{18: 0} \mathrm{Me}$ & $1 \cdot 3$ & - & - & $7 \cdot 9$ & - & $18 \cdot 0$ & - & $11 \cdot 3$ \\
\hline$C_{18: 1}$ & $6 \cdot 1$ & - & $1 \cdot 3$ & - & - & - & $1 \cdot 6$ & - \\
\hline$C_{19: 0}^{1001}$ & - & - & - & $1 \cdot 2$ & - & - & - & - \\
\hline $\mathrm{C}_{19: 0} \mathrm{Me}$ & $7 \cdot 0$ & - & 1.8 & - & $1 \cdot 0$ & - & $3 \cdot 3$ & - \\
\hline$C_{19: 1}^{19.0}$ & $14 \cdot 1$ & - & $7 \cdot 6$ & 2.5 & - & 5.7 & $1 \cdot 4$ & - \\
\hline $\mathrm{C}_{20: 0} \mathrm{Me}$ & $1 \cdot 0$ & - & - & - & - & - & $1 \cdot 2$ & - \\
\hline $\mathrm{C}_{20: 1}$ & $2 \cdot 8$ & & - & - & - & - & - & - \\
\hline Total & 100 & $\mathbf{0}$ & 60.9 & $39 \cdot 1$ & 23.9 & $76 \cdot 1$ & $34 \cdot 0$ & 66.0 \\
\hline
\end{tabular}

well documented effects of temperature on the composition of lipids in cell membranes, such variation is not unexpected.

\section{Effect of position of halogen substitution}

An investigation was conducted into the effect on fatty acid composition of $R$. rbodocbrous cells of altering the position of halogen substitution in the haloalkane growth substrate from the terminal position to the sub-terminal position using 1-bromododecane and 2-bromododecane as growth substrates (Table 4). The overall incorporation of bromofatty acids into the lipid fraction was very similar with the two substrates, suggesting that the position of halogen substitution in the haloalkane was not critical in determining the extent of incorporation of haloacids into the cellular lipids. The principal difference in composition between the lipids derived from growth on the two substrates was the presence of $(\omega-1)$-bromofatty acids in the 2-bromododecane-grown cells instead of the $\omega$ bromofatty acids of the 1-bromododecane-grown cells. No 2-bromofatty acids could be detected in lipids from $R$. rbodochrous cells grown on 2-bromododecane, indicating either that the oxygenase was unable to attack the 1 -position of 2-bromododecane or that, if attack does occur, the 2-bromododecanoic acid so formed is rapidly metabolized by $\beta$-oxidation with the two-carbon fragment containing the bromine atom being eliminated as bromoacetic acid.

\section{Concluding remarks}

The apparent ease with which a wide range of long-chain haloalkanes are assimilated into the component lipids of the haloalkane-degrading organism $R$. rhodocbrous has important implications for the biological treatment of haloalkane-containing effluent. Harvesting and safe disposal of biomass after such treatment may be necessary to prevent potentially toxic haloanalogues of normal fatty acids entering the biological food chain.

In the wider context there is increasing evidence that chlorofatty acids are widespread in the environment, particularly in fish lipids. Hitherto, the determination of organochlorine components in lipids has employed techniques specifically targeted on various man-made pollutants such as the organochlorine insecticides and polychlorinated biphenyls or has involved saponification of the triglyceride fraction which results in the elimination of chlorine as chloride from most chlorinated aliphatic compounds. However, recent investigations using enzymic and other non-destructive techniques have 
Table 4. Fatty acid composition of $R$. rhodochrous after growth at $25^{\circ} \mathrm{C}$ on 1-bromododecane and 2-bromododecane

Values are expressed as the percentage of total fatty acid content. Abbreviations: Non $\mathrm{Br}$, non-brominated fatty acid; $\mathrm{Br}$, $\omega$-bromofatty acid; $(\omega-1) \mathrm{Br},(\omega-1)$-bromofatty acid; $\mathrm{Me}$, methyl-branched fatty acid.

\begin{tabular}{|c|c|c|c|c|}
\hline \multirow[t]{3}{*}{ Fatty acid } & \multicolumn{4}{|c|}{ Growth substrate } \\
\hline & \multicolumn{2}{|c|}{ 1-Bromododecane } & \multicolumn{2}{|c|}{ 2-Bromododecane } \\
\hline & Non Br & $\mathbf{B r}$ & Non Br & $(\omega-1) \mathrm{Br}$ \\
\hline $\mathrm{C}_{8: 0}$ & - & $1 \cdot 6$ & - & - \\
\hline$C_{10: 0}$ & $1 \cdot 2$ & $1 \cdot 2$ & - & - \\
\hline$C_{12: 0}$ & $5 \cdot 3$ & $7 \cdot 8$ & - & $5 \cdot 0$ \\
\hline$C_{14: 0}$ & $6 \cdot 0$ & $1 \cdot 4$ & $7 \cdot 7$ & $2 \cdot 9$ \\
\hline$C_{15: 0}$ & $3 \cdot 3$ & - & $4 \cdot 8$ & - \\
\hline$C_{16: 0}$ & $26 \cdot 8$ & $1 \cdot 2$ & $27 \cdot 9$ & $2 \cdot 3$ \\
\hline$C_{16: 1}$ & $5 \cdot 0$ & - & $2 \cdot 8$ & - \\
\hline$C_{17: 0}$ & - & - & $2 \cdot 3$ & - \\
\hline $\mathrm{C}_{17: 0} \mathrm{Me}$ & $1 \cdot 6$ & - & 1.9 & - \\
\hline $\mathrm{C}_{17: 1}$ & - & - & $1 \cdot 4$ & - \\
\hline $\mathrm{C}_{18: 0} \mathrm{Me}$ & - & - & $1 \cdot 5$ & - \\
\hline$C_{18: 1}$ & $13 \cdot 2$ & $11 \cdot 7$ & $5 \cdot 8$ & 16.9 \\
\hline $\mathrm{C}_{19: 0} \mathrm{Me}$ & $7 \cdot 4$ & $1 \cdot 0$ & $10 \cdot 3$ & $2 \cdot 2$ \\
\hline$C_{19: 1}$ & $1 \cdot 4$ & - & $1 \cdot 4$ & - \\
\hline $\mathrm{C}_{20: 0} \mathrm{Me}$ & - & - & $2 \cdot 9$ & - \\
\hline$C_{20: 1}$ & $2 \cdot 9$ & - & - & - \\
\hline Total & $74 \cdot 1$ & $25 \cdot 9$ & $70 \cdot 7$ & $29 \cdot 3$ \\
\hline
\end{tabular}

demonstrated that a substantial proportion of organically bound chlorine in fish lipids is associated with fatty acids present in triglycerides. Thus, Wesén et al. (1992) have shown that fatty acids comprised $90 \%$ of the 1200 p.p.m. extractable organically bound chlorine present in eel lipids. Similarly, a large proportion of the organically bound chlorine in bivalves has been identified as halogenated fatty acids (Wesén $e t$ al., 1995). As yet there is no evidence as to whether these chlorinated lipids are of natural or anthropogenic origin.

Long-chain fatty acid chlorohydrins have been identified as natural products in a species of edible jelly fish (White \& Hager, 1977) and could possibly enter the marine food chain from such a source. Certain chlorinated fatty acids are known to be formed in pulp mill bleaching processes (Leach \& Thakore, 1977) and observations referred to by Sundin et al. (1993) suggest that they can be incorporated into fish lipids. Another possible man-made source of such compounds are the chlorinated paraffins widely used as plasticizers and contained in lubricants, paints and fire retardants; the total world production is estimated to be of the order of 300000 tonnes per year (Houghton, 1991). Investigations to date have not indicated significant bioaccumulation of these compounds as such (Campbell \& McConnell, 1980), nor given evidence of appreciable toxicity to fish or birds (Madeley \& Birtley, 1980). Nevertheless, chloroparaffins, although incapable of sustaining microbial growth alone, can undergo co-metabolic degradation by $n$-alkane-degrading bacteria leading to the production of a variety of chlorinated long-chain fatty acids (Omori et al., 1987). A proportion of such acids can be further degraded in mixed culture with mineralization of between 15 and $60 \%$ of chlorine, depending on the type of chlorinated paraffin under study. However, some of the chlorinated fatty acids formed appear resistant to further breakdown. The work described in this paper indicates a mechanism by which such bacterial degradation products could enter the biological food chain.

\section{ACKNOWLEDGEMENTS}

The authors wish to thank Ms Orla Flynn for her skilled technical assistance in microbial culture.

\section{REFERENCES}

Campbell, I. \& McConnell, G. (1980). Chlorinated paraffins and the environment. 1. Environmental occurrence. Environ Sci \& Tecbnol 14, 1209-1214.

Curragh, H., Flynn, O., Larkin, M. J., Stafford, T. M., Hamilton, J. T. G. \& Harper, D. B. (1994). Haloalkane degradation and assimilation by Rhodococcus rbodochrous NCIMB 13064. Microbiology 140, 1433-1442.

Dunlap, K. R. \& Perry, J. J. (1967). Effect of substrate on the fatty acid composition of hydrocarbon-utilizing microorganisms. J Bacteriol 94, 1919-1923.

Houghton, K. L. (1991). Chlorinated paraffins. In Encyclopedia of Chemical Technology, 4th edn, vol. 6, pp. 78-87. Chichester: J. Wiley $\&$ Sons.

King, D. H. \& Perry, J. J. (1975). Characterization of branched and unsaturated fatty acids in Mycobacterium vaccae strain JOBS. Can J Microbiol 21, 510-512.

Leach, J. M. \& Thakore, A. N. (1977). Compounds toxic to fish in pulp mill waste streams. Prog Water Technol 9, 787-798.

Madeley, J. R. \& Birtley, R. D. N. (1980). Chlorinated paraffins and the environment. 2. Aquatic and avian toxicology. Environ Sci \& Technol 14, 1215-1221.

Murphy, G. L. \& Perry, J. J. (1983). Incorporation of chlorinated alkanes into fatty acids of hydrocarbon-utilizing mycobacteria. $J$ Bacteriol 156, 1158-1164.

Murphy, G. L. \& Perry, J. J. (1984). Assimilation of chlorinated alkanes by hydrocarbon-utilizing fungi. J Bacteriol 160, 1171-1174.

Omori, T. \& Alexander, M. (1978). Bacterial dehalogenation of halogenated alkanes and fatty acids. Appl Environ Microbiol 35, 867-871.

Omori, T., Kimura, T. \& Kodama, T. (1987). Bacterial cometabolic degradation of chlorinated paraffins. Appl Microbiol Biotechnol 25, 533-557.

Sundin, P., Wesén, C., Mu, H. \& Odham, G. (1993). Are chlorinated fatty acids in fish lipids of natural origin? Abstracts of Posters at the 1st International Conference on Naturally-produced Organobalogens, pp. 31-33. Delft, The Netherlands, September, 1993.

Wesén, C., Mu, H., Kvernheim, A. L. \& Larsson, P. (1992). Identification of chlorinated fatty acids in fish lipids by partitioning studies and by gas chromatography with Hall electrolytic conductivity detection. J Chromatogr 625, 257-269. 
Wesén, C., Mu, H., Sundin, P., Ringstad, O. \& Odham, G. (1995). Occurrence of halogenated fatty acids in bivalve lipids. In Naturallyproduced Organohalogens, pp. 307-316. Edited by A. Grimvall \& E. W. B. de Leer. Dordrecht: Kluwer Academic Publishers.

White, R. H. \& Hager, R. H. (1977). Occurrence of fatty acid chlorohydrins in jellyfish lipids. Biocbemistry 16, 4944-4948.
Yokata, T., Fuse, H., Omori, T. \& Minoda, Y. (1986). Microbial dehalogenation of haloalkanes mediated by oxygenase or halidohydrolase. Agric Biol Chem 50, 453-460.

Received 13 April 1995; revised 13 June 1995; accepted 26 June 1995. 